\title{
Dynamic Fiscal Policies and Endogenous Growth
}

\author{
Hyun Park \\ Kyung-Hee University \\ Apostolis Philippopoulos \\ Athens University of Economics and Business
}

\begin{abstract}
This paper studies the dynamic properties of an endogenous growth model in which government consumption and production services are financed by capital taxes. I generalize the existence and its stability property of commitment Ramsey equilibria when government spending is productive and taxation is distortionary. I then establish a sufficient condition for uniqueness of the (positive) balanced growth path and determinacy of transitional dynamics. The same sufficient condition ensures growth convergence in Barro-type endogenous fiscal policies. This modeling approach can be used by a large class of endogenous growth models which allow for market imperfections and optimal policies. In particular, a few implications for main results are discussed on economic integration.
\end{abstract}

- JEL Classifications: D90, H21, O38

- Key words: Optimal tax policy, Transitional dynamics, Determinacy, Growth convergence

\section{Introduction}

General equilibrium models of endogenous growth have studied the role of fiscal policy in the growth process. ${ }^{1}$ The main idea is that a government provides growth-enhancing public capital for the private production processes. The provision of productive government spending can be thought of as education, R\&D subsidy, and public infrastructures. For this reason, at the aggregate level, there are

\footnotetext{
*Corresponding address: Hyun Park, Department of Economics, Kyung-Hee University, 1 Hoegi-dong, Dongdaemun-gu, Seoul 130-701, Korea, Tel: +82-2-961-9375, Fax: +82-2-966-7426, E-mail: econhyun@ khu.ac.kr

@2005-Center for International Economics, Sejong Institution, All Rights Reserved.
} 
no diminishing returns, and hence the economy is capable of long-run endogenous growth. If government expenditures are financed by distorting taxes, this raises several questions regarding the optimal level of government expenditures and the associated optimal tax rate: For instance, does an optimal tax rate exist to support persistent growth? If it does, is it unique or determinate? Is it optimal to keep the tax rate constant over time, as in the tax-smoothing model? Is the long-run growth path dynamically stable?

The usual framework for studying optimal fiscal policies in a growing economy is the Barro-type public finance model á la Barro [1990]. This is analytically simple to incorporate productive public services and distortionary tax policies. As result, Barro [1990], Barro and Sali-i-Martin [1995], Alesina and Rodrik [1994] and Devereux and Wen [1998] show that the optimal income tax rate is constant over time and there are no transitional growth dynamics. Recently, Benhabib and Velasco [1996] and Benhabib, Rustichini and Velasco [1996] have introduced a more general production functions to ensure that the optimal capital tax rate is always constant over time. It is interesting to investigate the robustness of socially optimal dynamic state-independent fiscal policies in models in which government polices play an important role of long-run growth.

Building on the above studies, ${ }^{2}$ the present paper introduces an endogenous growth model, in which the government optimally chooses a path of distorting capital tax rates to finance both consumption and production public services (see also Lee [1992] and Cazzavillan [1996]) $)^{3}$. A large class of endogenous growth models, which allow for optimal economic policies, can use this modeling approach. It is natural to discuss a few implications for economic integration. This paper makes three contributions to the literature. First, I generalize the properties of the optimal tax policy in Barro [1990]. Second, I establish a sufficient condition for existence and uniqueness of the balanced growth path (BGP), as well as a unique

\footnotetext{
${ }^{1}$ For a survey of the literature on growth and the public sector, see e.g. Glomm and Ravikumar [1997] and Agell et al. [1997]. For empirical evidence see e.g. Devarajan et al. [1996] and Kneller et al. [1999].

${ }^{2}$ This work differs from Benhabib, Roustichini and Velasco [1996] who focus on the time-consistency issue and the properties of the optimal tax plan under different commitment technologies, i.e. the Chamley-Judd-Lucas result. It also differs from Benhabib and Velasco [1996] who study the special case of a small open economy in which the after-tax return to domestic capital equals the exogenously given world interest rate.
}

${ }^{3}$ In contrast with the model in this paper, Lee [1992] and Cazzavillan [1996] consider fixed, constant income tax over time to finance public spending. Hence, they abstract from intertemporal distortionary effects of taxes. 
transition path to the BGP. Third, I extend the local stability for a non-growing economy as in Judd [1985] and Chamley [1986] to for a persistently growing economy. ${ }^{4}$ Finally, I show that the same condition in fact ensures growth convergence in endogenous growth models with productive public services and distortionary taxes.

In a generalized version of public-finance endogenous growth models, I characterize a commitment equilibrium with a benevolent government playing as the Stackelberg leader vis-a-vis the private sector followers. ${ }^{5}$ This is well-known a Ramsey (second-best) fiscal policy. ${ }^{6}$ Provision of government consumption services implies that the optimal capital tax rate is not constant, but changes over time, and hence there are endogenous growth dynamics, even if technology at the firm's level has the standard Cobb-Douglas form. This enriches the results of Benhabib, Rustichini and Velasco [1996] who employ more general CES production functions than Cobb-Douglas to derive endogenous growth dynamics. Moreover, the optimal long-run tax rate is higher than the flat tax rate of Barro [1990] and does not tend to be zero in the long run (i.e. Judd [1999], Chamley [1986]).

Three features of Ramsey optimal policy in growing economies are of particular interest. First, the two possible policy instruments (e.g. the capital tax rate and the portion of total tax revenues used to finance public production services) are substitutes along the optimal path. It is convenient for our purpose to choose tax rate as a policy instrument. Intuitively, when the government allocates a larger share of tax revenues to public production services, it can afford a lower tax rate since public production services stimulate private investment and hence increase the tax base. Second, since the government also provides public consumption services, the optimal tax rate is all the time higher than in Barro [1990], where the necessary conditions for optimality require that the tax rate should be kept constant over time and equal to the productivity of public services. As a result, in this model, the policy that maximizes the utility of the representative household implies

\footnotetext{
${ }^{4}$ Lucas [1990] also consider optimal taxation problem in a growing economy, but unlike this paper, he focus on the flat taxation and do not examine the stability property of fiscal policies.
${ }^{5}$ An alternative way of endogenizing economic policy is to suppose that private agents vote on the path of fiscal policy. For endogenous growth with voting, see e.g. Glomm and Ravikumar [1997] and Krusell, Quadrini and Rios-Rull [1997].

\footnotetext{
${ }^{6}$ See Dreze and Stern [1987] and Stiglitz [1987] for survey papers on optimal taxation in second-best environments with market imperfections and distorting taxes.
} 
that the optimal tax rate (resp. the optimal share of tax revenues used to finance public production services) is higher (resp. lower) than the one that would maximize the rate of growth. Third, the government finds it optimal to accomplish its allocation task by not following state-contingent policy rules. ${ }^{7}$ That is, the optimal tax that allows the finance of public services, as well as the optimal allocation of the collected tax revenues to the various types of public services, are both independent of the state of the economy (here, the inherited capital stock). The intuitive reason is that nonstate-contingent policies introduce fewer distortions.

I also investigate the possibility of uniqueness (or determinacy) of equilibria. As I said above, I show existence of a unique BGP, as well as a unique transition path. These results are consistent with those of Benhabib and Perli [1994] who state that externalities (even large ones) are not enough to produce multiplicity. They are also consistent with the result of Benhabib and Gali [1995], i.e. as long as the uniqueness of the steady state is preserved, the uniqueness of the equilibrium trajectory is also preserved even in the presence of market imperfections (here, in the form of production externalities).

Determinacy is equivalent to growth convergence to a steady state BGP. That is, the sufficient condition for determinacy also guarantees growth convergence. This is because determinacy is equivalent to saddle-stability. This verifies Lucas' [1988] conjecture that all Ramsey equilibrium paths converge to a balanced growth rate. $^{8}$ These results show that this also applies to endogenous growth models with productive public services and distorting taxes (see also Basu and Weil [1998]). More importantly, this property, including uniqueness of BGP, permits us to analyze the comparative dynamics of optimal policies in a growing economy.

The above properties of the model have the following implications in an integrated economy. First, a hierarchical decision structure in the integrated economy is likely to lead to a Ramsey (second-best) policy. Hence, this simple general equilibrium model is natural to the integrated economy. Second, in a federation system as in the U.S., Canada, EU and many others, the provision of government consumption is in common and thus government fiscal policies are

\footnotetext{
${ }^{7}$ By introducing a state-contingent capital tax scheme Guo and Lansing [1999] show local and global indeterminacy of equilibria. They also show possibilities of bifurcation and whereby business cycles and sunspots. However, their results mainly depend on increasing returns and social externalities in the aggregate production.

${ }^{8}$ However, this is not the usual turnpike property in the sense that convergence occurs at a rate rather than at a level. Convergence results for the latter are surveyed in McKenzie [1987].
} 
likely to be time-dependent. Thus, the above non-constant optimal path implies that the Friedman's policy rule is less efficient in the integrated economy with consumptive government spending. Third, rule-base government policies, rather than discretion policies, can be socially inefficient in the integrated economy since the optimal policy is state-contingent.

The rest of the paper is as follows. Section II presents the economic environment. Section III solves for second-best Ramsey policy and analyzes the resulting dynamics. Section IV contains the conclusions.

\section{The Economic Environment}

This paper sets up a decentralized, closed economy with a private sector and a government sector. The private sector acts competitively, and consists of a representative household and a representative firm. The representative household consumes, rents out its assets to the firm, and supplies inelastically one unit of labor per period of time. ${ }^{9}$ The representative firm produces output by using capital, labor, and government service. The government taxes the firm's installed capital in order to provide production and consumption services. ${ }^{10}$ The household and the firm treat these services as public goods. The government is benevolent and, when it chooses its policy, it can commit itself to a second-best tax policy. There is no population change and no depreciation on capital. The economy is assumed to be continuous time, infinite horizons and perfect foresight.

The Representative Household's Problem: The representative household maximizes intertemporal utility, given public consumption services, $x$ :

$$
\int_{0}^{\infty} u(c, x) e^{-\rho t} d t
$$

where $c$ is private consumption and the parameter $\rho>0$ is the rate of time preference. ${ }^{11}$ The function $u(c, x)$ is increasing and concave in its two arguments. It

\footnotetext{
${ }^{9}$ Ortigueira [2000] extends uniqueness and stability. Combing elastic labor supply and leisure in a felicity can lead to indeterminacy. See, for example, Benhabib and Perli [1994] and Turnovsky [2000].

${ }^{10} \mathrm{My}$ results do not change if I use income taxes. This is because this model is (at an aggregate level) a variant of Rebelo's [1991] $A K$ model. Also see below.

${ }^{11}$ Cazzavillan [1996] also considers the model of public consumption and focuses on existence of multiple steady states and constructs the sunspot equilibrium growth path and endogenous stochastic fluctuation, providing public consumption services involve increasing returns.
} 
also satisfies the Inada conditions. For simplicity and supporting balanced growth paths, the utility function is additively separable and logarithmic. ${ }^{12}$ Thus,

$$
u(c, x)=\log c+\gamma \log x
$$

where the parameter $\gamma \geq 0$ is the weight given to public consumption services relative to private consumption.

The household saves in the form of capital. Thus, if $k$ denotes capital, the household receives interest income $r k$. Also, the household supplies inelastically one unit of labor services per period of time so that its wage income is $w$. It also receives net profits $\pi$. Thus, the flow constraint for the representative household is:

$$
c+\dot{k}=r k+w+\pi
$$

where a dot over a variable denotes time derivative.

The household acts competitively by taking prices, economic policy and public goods as given. Technically, the control variables are $c$ and $\dot{k}$. Hence, the firstorder conditions for utility maximization are equation (3) and the Euler condition:

$$
\dot{c}=c(r-\rho)
$$

The necessary conditions (3) and (4) are completed with the addition of the transversality condition $\lim _{t \rightarrow \infty}\left[u_{c} k e^{-\rho t}\right]=0$, where $u_{c} \equiv \partial u(c, x) / \partial c .{ }^{13}$ It is clear that there exists a unique solution to the household's problem (see e.g. Chapter 2, Barro and Sala-i-Martin [1995]).

The Representative Firm's Problem: As in Benhabib, Rustichini and Velasco [1996] and Benhabib and Velasco [1996], the government taxes the representative firm's capital stock, $k$, carried over from the previous period. Then, if $0 \leq \tau<1$ is the tax rate on capital, $(1-\tau) k$ is the net capital stock used in production in the

\footnotetext{
${ }^{12}$ These results do not change if I use more general functions, e.g. $\left[c^{1-\sigma} /(1-\sigma)\right]+\gamma\left[x^{1-\varepsilon} /(1-\varepsilon)\right]$, where $\sigma, \varepsilon>0$. However, see Section IV below for separability. A possible extension to non-separable utility, e.g., a recursive utility function á la Chamley [1986], is not obvious in a continuous time model.

${ }^{13}$ Notice that the utility function of the other argument $x$ must also be bounded. See below that capital as well as public consumption services grows at a constant rate and thereby this transversality condition ensures the boundedness of lifetime utility.
} 
current period. Also, as in Barro [1990], Glomm and Ravikumar [1997] and Turnovsky [2000], technology takes a Cobb-Douglas form so that the firm faces the production function - written in intensive form:

$$
y=g^{1-\alpha}[(1-\tau) k]^{\alpha}
$$

where $y$ is output, $g$ is public production services and $0<\alpha<1$ is a parameter. Then profit for a representative firm is:

$$
\pi=y-r k-w
$$

The firm acts competitively by taking prices, economic policy and public goods as given. Of course, the firm's problem is well defined since the production function is increasing and concave and satisfies the Inada condition. The control variable is $k$ so that the first-order condition for profit maximization is:

$$
r=\alpha(1-\tau) g^{1-\alpha}[(1-\tau) k]^{\alpha-1}
$$

which equates the rate of return to the after-tax marginal product of capital.

The Government Budget Constraints: At each point of time, the government runs a balanced budget financed by a tax rate, $0 \leq \tau<1$, on capital, $k$. Thus,

$$
g+x=\tau k
$$

where I assume:

$$
\begin{gathered}
\mathrm{g}=\theta \tau k \\
\mathrm{x}=(1-\theta) \tau k
\end{gathered}
$$

where the parameter $0<\theta<1$ is the share of tax revenues used for production services and $1-\theta$ for consumption services. I assume that $\theta$ is exogenous and constant over time so as to study how decomposition between consumption and production public services affects the dynamics of optimal growth and tax policy. ${ }^{14}$

\footnotetext{
${ }^{14}$ See also Turnovsky and Fisher [1995] for the (exogenous) decomposition of government expenditures between consumption and production services. For endogenous decomposition for public services, it is easy to show the optimal tax rate $\tau$ is interdependent on $\theta$. When both $\tau$ and $\theta$ are optimally chosen, we have an additional condition $-\gamma+\left(\lambda_{c} c+\lambda_{k} k\right)(1-\theta) \Delta_{\theta}=0$ together with (13a). Therefore, we have that $-(1-\tau) /(1-\alpha-\tau)=\theta$ / $(1-\alpha)(1-\theta)$. Thus, $\tau$ and $\theta$ has a negative relation, i.e. when the government allocates a larger share of tax revenues to the public production services, it can afford a lower tax rate. Hence, $\tau$ and $\theta$ are substitutes along the optimal path. This implies that either a tax rate and decomposition of expenditure: $\tau, \theta$ can be chosen as an optimal policy instrument. Furthermore, main properties for the equilibrium paths with either exogenous or endogenous $\theta$ are qualitatively identical (see details in Park and Philippopoulos [2003]).
} 
It also helps me to make these results comparable to those of the relevant literature (see below).

Decentralized Competitive Equilibrium: I now characterize a Decentralized Competitive Equilibrium (DCE) for any given policy. Since as (8a)-(8c) show, only two of the three policy instruments $(g, x, \tau)$ can be independently set, I choose to express the DCE in terms of the tax rate, $\tau$.

By substituting (8b) into (7), I get:

$$
r=\alpha(\theta \tau)^{1-\alpha}(1-\tau)^{\alpha}
$$

which is the return to capital perceived by private agents in a DCE. This is the return that drives private consumption/saving decisions in a decentralized equilibrium (see (3) and (4) above). In the presence of externalities, this return $r$ is smaller than the realized return $\hat{r}$. It is easy to see as follows: Using (8b) into (5), the economy-wide output is $y=\left[(\theta \tau)^{1-\alpha}(1-\tau)^{\alpha}\right] k,{ }^{15}$ where $k$ is the capital stock that has been chosen by private agents who ignored externalities. Therefore, the realized returns to capital is $\hat{r} \equiv \partial y / \partial k=\left[(\theta \tau)^{1-\alpha}(1-\tau)^{\alpha}\right]$. That is, $r=a \hat{r}$. This justifies government intervention in the next section.

To get the private agents' optimal decision rules in DCE, I also need to calculate realized labor income and profits at an economy-wide level, $w+\pi$. Recall that $y=\left[(\theta \tau)^{1-\alpha}(1-\tau)^{\alpha}\right] k$, where $k$ is the capital stock that has been chosen by private agents who ignored externalities. I also know that realized capital payments, labor income and profits exhaust total output at an equilibrium: $y=\hat{r} k+w+\pi$, where $\hat{r} \equiv \partial y / \partial k=\left[(\theta \tau)^{1-\alpha}(1-\tau)^{\alpha}\right]$. Hence, $w+\pi=y-\hat{r} k=0$ to the household's budget. ${ }^{16}$ In other words, in a DCE, all realized income goes to capital. This

\footnotetext{
${ }^{15}$ Thus, the model is a variant of Rebelo's [1991] $A K$ model. That is, at the aggregate level output is linear in capital. However, here " $A$ " is affected by fiscal policy.

${ }^{16}$ Instead, one could claim that I should use the zero-profit condition, which implies that the wage rate equals the marginal product of labor. However, this is correct only when labor/leisure decisions are endogenous, so that they are driven by a perceived return to labor in a way similar to that for capital in (9); see e.g. Alesina and Rodrik [1994]. By contrast, there is one unit of labor which is supplied inelastically at $w$. Therefore, here I calculate realized labor income plus profits as a residual of what actually goes to capital, $\hat{r} k$. The same method is applied in Park and Philippopoulos [2003] in the context of income redistributive tax and endogenous growth. Noticeably, two methods coincide in the absence of externalities, i.e. when $\alpha=1$. This implies that identifying agent's perception of factor prices is critical for Ramsey fiscal policies in the presence of externalities.
} 
happens because this model is a variant of Rebelo's [1991] $A K$ model. If capital is paid its realized marginal product, there is nothing left for labor or profits, ex posts (also see Barro and Sala-i-Martin [pp. 141-142, 1995] and Park and Philippopoulos [2003]).

This completes the characterization of DCE. It is convenient for what follows, to present the private agents' optimal decision rules in DCE. Using $w+\pi=0$ and (9) for $\tau$ into (3) and (4), I get:

$$
\begin{gathered}
\dot{k}=\Delta k-c \\
\dot{c}=c(\Delta-\rho)
\end{gathered}
$$

where $\Delta \equiv\left[\alpha(\theta \tau)^{1-\alpha}(1-\tau)^{\alpha}\right]$ as in $(9) .{ }^{17}$

I summarize this section. This paper has characterized a Decentralized Competitive Equilibrium. This is for any tax policy $\tau$. In this equilibrium: (a) Private decisions maximize households' utilities and firms' profits (see (10) and (11)); (b) The government balances budget constraints each point in time as summarized by $(8 b)$ and $(8 c)$.

\section{Dynamic Tax and Spending Policy}

I now endogenize economic policy. The government maximizes the utility of the representative household and plays as the Stackelberg leader vis-a-vis the private sector followers. ${ }^{18}$ That is, the government takes into account the optimal behavior of private agents, households and firms, and its own budget constraint. This is a Ramsey problem (see e.g. Judd [1999], Lucas [1999], Lucas and Stokey [1983],

\footnotetext{
${ }^{17}$ The similarity of realized returns to socially optimal ones obscures an important difference between them: realized returns correspond to individual decisions, $k$, which ignored externalities.

${ }^{18}$ An alternative way of endogenizing government policies is to suppose private agents vote on fiscal policy (see Alesina and Rodrik [1994]). Moreover, the institutional setup is critical for decision process. It is often between full decentralization and full federation. The democratic federation (Inman and Rubinfeld [2002]) aims to combine benefits of decentralized federalism with efficiency advantages of centralized decision. In addition, a hierarchal decision structure also matters for efficiency of fiscal policies. For example, the EU system captures the situation that the federation has more commitment power and its policy choices are less easily reversible than the national choices. One the other hand, the US system is rather horizontally organized as opposed to that the EU system is vertically ordered (see details in Persson and Tabellini [pp. 636, 1996]).
} 
and Chamley [1986]). ${ }^{19}$ I assume commitment technologies on behalf of the government, so that decisions are made once-and-for-all and a solution is an openloop equilibrium.

The government chooses its policy to maximize (1)-(2) subject to (10) and (11), where $x$ follows (8c). The current-value Hamiltonian, $H$, of this problem is:

$$
H \equiv \log c+\gamma \log [(1-\theta) \tau k]+\lambda_{c} c(\Delta-\rho)+\lambda_{k}(\Delta k-c)
$$

where $\lambda_{\mathrm{c}}$ and $\lambda_{k}$ are the multipliers associated with (10) and (11) respectively (see Chamley [1986] for interpretation). Let . The necessary conditions with respect to and are given by (13a), (13b), (13c), (13d) and (13e) respectively:

$$
\begin{gathered}
\gamma / \tau+\left(\lambda_{c} c+\lambda_{c} k\right) \Delta_{\tau}=0 \\
\dot{\lambda}_{c}=\rho \lambda_{c}-1 / c-\lambda_{c}(\Delta-\rho)+\lambda_{k} \\
\dot{c}=c(\Delta-\rho) \\
\dot{\lambda}_{k}=\rho \lambda_{k}-\lambda_{k} \Delta-\gamma / k \\
\dot{k}=\Delta k-c .
\end{gathered}
$$

These necessary conditions are completed with the addition of the transversality condition:

$$
\Delta-\rho<\rho
$$

which also ensures utility is bounded. ${ }^{20}$ That is, the positive long-run growth rate of consumption, $(\Delta-\rho)>0$, is less than the discount rate, $\rho>0$. In fact, this transversality condition is not needed providing the saddle-stability property of an equilibrium allocation (see Proposition 3 in Section III).

\footnotetext{
${ }^{19}$ Thus, the government is constrained by the private agents' optimal decision rules. This is because the economy is decentralized. In other words, I do not solve a social planner's problem. The path of optimal capital tax generalizes the time-invariant tax rate in Lucas and Stokey [1983] and Futagami et al. [1993].

${ }^{20}$ Capital cannot grow faster than consumption (see below). Hence, the utility from government consumption services is also bounded if (13f) is satisfied.
} 
Since the utility function and the constraints are continuous and bounded, and since the utility function is strictly concave in the controls, $c$, $\tau$; and the constraints are linear in $c$ and strictly concave in $\tau$, existence is assured. It is clear from $\Delta_{\tau \tau}<0$. Further, since the utility function and the constraints are both jointly concave in the controls, $c, \tau$; and the state variable, $k$, the government's problem is well-defined. Moreover, Arrow's sufficiency theorem (Seierstad and Sydsæter [1987]) implies that the necessary conditions, (13a)-(13f) are also sufficient for optimality. This establishes existence of a solution for optimal policy and a growing equilibrium path.

Before proceeding, I consider the special case in which government consumption services provide no direct utility, i.e. $\gamma=0$ in equation (2). Then, (13a) implies either $\left(\lambda_{c} c+\lambda_{k} k\right)=0$ or $\Delta_{\tau}=0$. The former case, i.e. $\left(\lambda_{c} c+\lambda_{k} k\right)=0$, cannot occur because it contradicts the dynamic equations (13b)-(13e). ${ }^{21}$ The latter case, i.e. $\Delta_{\tau}=0$, implies $0<\tau=1-\alpha<1$ in all time periods. Note that this case can be thought as a version of the tax-smoothing model as in Barro [1990]. Also note that since a constant $\tau$, in addition to a constant $\theta$, implies a constant $\Delta,(13 \mathrm{c})$ and (13e) imply that the economy has no transitional dynamics. That is, when $\gamma=0$, the economy should adjust immediately to its steady state, balanced growth path. These results generalize the constant optimal tax rate in optimal growth models with productive fiscal policies (see e.g. Barro [1990], Glomm and Ravikumar [1997], Turnovesky [2000]). Therefore, when $\gamma>0$, the optimal tax rate is not constant over time, and so the economy has transitional dynamics.

Equations (13a)-(13e) constitute a system of five equations in $\tau, c, \lambda_{c}, k, \lambda_{k}$. Following usual practice, I reduce its dimensionality to facilitate analytical tractability. Taking logarithms on both sides of equation (13a), differentiating with respect to time, and using (13b), (13c), (13d) and (13e), I get after some manipulation:

$$
\dot{\tau} / \tau=\left[-1-\left[\Delta_{\tau \tau} / \Delta_{\tau}\right]\right]^{-1}[\rho+[(1+\gamma) / \gamma][(1-\alpha-\tau) \Delta /(1-\tau)],
$$

which describes the dynamics of $\tau$ and $\Delta_{\tau \tau} / \Delta_{\tau}=-\alpha(1-\alpha) / \tau(1-\tau)(1-\alpha-\tau)$. Next, by defining $z \equiv c / k$ to be the consumption-to-capital ratio, I obtain from equations (13c) and (13e):

\footnotetext{
${ }^{21}$ In particular, differentiation of $\lambda_{c}+\lambda_{k} k=0$ with respect to time gives an expression that contradicts the other first-order conditions (13b)-(13e). See also below.
} 


$$
\dot{z} \equiv z^{2}-\rho z
$$

which describes the dynamics of $z$.

Therefore, the original five-dimensional system (13a)-(13e) in $\tau, c, \lambda_{c}, k, \lambda_{k}$ has been reduced to the two-dimensional system (14a)-(14b) in terms of $\tau, z$. The dynamics of the latter are equivalent to those of the former. The rest of this section studies the steady state and transitional dynamics of (14a)-(14b). Before I do so, I summarize the main result of this subsection:

Proposition 1: If the government provides public consumption services, the optimal (second-best) capital tax rate is not constant over time and the economy has transitional endogenous growth dynamics.

This generalizes Barro [1990] and Alsena and Rodrik [1994], and also enriches Benhabib, Rustichini and Velasco [1996]. That is, the optimal tax rate changes over time, even if technology at the firm's level is Cobb-Douglas. ${ }^{22}$ It suggests that the second-best capital tax cannot eliminate the intertemporal distortions from positive externality of public services. More importantly, this implies that the Friedman rule may not be optimal in the presence of public goods and tax distortion (see Chari and Kehoe [1999] for details).

Steady State Balanced Growth Path: A balanced growth path (BGP) is defined to be a steady state in which: (i) Consumption, $c$, and capital, $k$, grow at a positive constant rate. Then, they must grow at the common rate (see below for the argument). This implies that $z \equiv c / k$ is a constant, or equivalently $\dot{z}=0$ in (14b). (ii) The tax rate does not change. Thus, $\dot{\tau}=0$ in (14a). Let us denote these BGP values of $(\theta, z)$ by $(\tau, \tilde{z})$. This subsection solves for $\tau$ and $\tilde{z}$.

I start with $\tilde{\tau}$ in $(14 a)$. Recall that $(1-\alpha-\tau) \neq 0$ from (13a). Then, it must be $\rho(1-\tau)+((1+\gamma) / \gamma)(1-\alpha-\tau) \Delta=0$ for $\dot{\tau}=0$ to hold. Using the definition for $\Delta$ above, this implies the following expression for $\tau$ :

$$
\Omega(\tau) \equiv \alpha((1+\gamma) / \gamma)(1-\alpha-\tau)[\theta \tau /(1-\tau)]^{1-\alpha}=-\rho<0
$$

\footnotetext{
${ }^{22}$ This is not the only way to get transitional dynamics. For instance, Futagami et al. [1993] introduce productive public capital stocks to get transitional dynamics in a similar model. Cazzavillan [1996] also has non-trivial transitional dynamics with consumption externalities in utility and shows instability of a balanced growth path.
} 
This implies that $(1-\alpha-\tau)<0$. Although (15) cannot be solved analytically for $\tau$, it is easy to show that $\Omega(\tau)$ is monotonically decreasing, and continuous in $\tau \in(1-\alpha, 1)$. Therefore, there exists a unique $\tau$, which lies between $1-\alpha$ and 1 (i.e. $1-\alpha<\tau<1)$. I denote this solution for $\tau$ as $\tau=\tau(\alpha, \theta, \rho, \gamma)$.

Some interesting observation can be made. First, the optimal long-run Ramsey tax rate, $1-\alpha<\tau<1$, is higher than in Barro [1990] where $\tau=1-\alpha$. As I said above, only when public consumption services provide no utility, i.e. $\gamma=0$, it is optimal to set $\tau=1-\alpha$. When the government provides neither public consumption services, i.e. $\gamma=0$, nor public production services, i.e. $\alpha=1$, the optimal tax rate is zero, i.e. $\tau=0$. In this case, the equilibrium return to capital is not bounded below, i.e. $\Delta=0$, and hence long-run growth is not optimal. Therefore, it is public production services that generate long-run growth along an optimal path.

Second, partial differentiations of (15) with respect to variables $\alpha, \theta, \rho, \gamma$ imply:

$$
\tau=\tau(\bar{\alpha}, \bar{\theta}, \stackrel{+}{\rho}, \stackrel{+}{\gamma})
$$

where signs above variables indicate comparative static properties. This analysis is robust under the stability property in Proposition 3 below. First, when the productivity of government services in the production function increases (i.e. $\alpha$ decreases), the optimal tax rate increases. Second, when the government allocates a larger share of tax revenues to productive services (i.e. $\theta$ increases), it can afford a lower tax rate. Third, when the household cares more about the future (i.e. $\rho$ decreases), then the tax rate is lower in the BGP. Furthermore, this result is in contrast with the property of second-best capital tax as in Chamely [1986] and Judd [1999], in which the second-best optimal capital tax rate becomes zero in the short and long run. Finally, when the relative weight, $\gamma$, given to utility of public consumption services increases, the optimal tax rate has to increase. ${ }^{23}$ Note that these results make sense only when the balanced growth path is unique and stable. I will establish the stability property in Proposition 3 below. ${ }^{24}$

Third, I continue with $\tilde{z}$. Setting equation (14b) equal to zero, I simply have:

$$
\tilde{z}=\rho
$$

\footnotetext{
${ }^{23}$ Numerical simulations illustrate these analytical comparative static results and also give admissible values for $\tilde{\tau}$ in (15). See below.

${ }^{24} \mathrm{~A}$ similar convergence property in an $A K$ model is studied by Basu and Weil [1998].
} 
so that BGP consumption-to-capital ratio equals the discount factor.

Finally, I check whether the BGP values just found satisfy the transversality condition (13f), which requires $0<\rho<\Delta<2 \rho$. Since $\Delta \equiv \alpha(\theta \tau)^{1-\alpha}(1-\tau)^{\alpha}$, this imposes the following constraint on the optimal tax rate, $\tilde{\tau}$ :

$$
\psi<\tau^{1-\alpha}(1-\tau)^{\alpha}<2 \psi
$$

where $\psi \equiv \rho \alpha^{-1} \theta^{(1-\alpha)}>0$. In turn, since from equations (15)-(16) $\tau$ is a monotone function of $(\alpha, \theta, \rho, \gamma)$, condition (18) imposes restrictions on the admissible values of the structural parameters $(\alpha, \theta, \rho, \gamma)$ As mentioned, this transversality condition is always satisfied when the optimal balanced growth path is stable (see Proposition 3).

The above results for the steady state balanced growth path can now be summarized:

Proposition 2: If the parameters satisfy condition (18), there exists a unique long-run tax rate $\tau$, which supports a unique Balanced Growth Path (BGP) for consumption and capital.

This property is in contrast with that of Cazzavillan [1996], in which there are multiple steady states and sunspots equilibria are thereby constructed in models of public consumption and production service in a continuous time model.

A Numerical Example: Numerical experiments can show that, with $\tau$ being determined by (15), condition (18) is satisfied for various combinations of reasonable parameter values, i.e. $0<\alpha<1,0<\theta<1, \rho>0$, and $\gamma>0$. For instance, I choose the parameter values: $\alpha=0.9, \theta=0.9, \rho=0.34$ and $\gamma=1$, based on those in Lucas [1988] except $\gamma .{ }^{25}$ Then, equation (15) implies that $1-\alpha<\tau=0.3<1$. These values also satisfy the persistent growth condition and the transversality condition (see (18)), since $\psi=0.38$ and $\tau^{1-\alpha}(1-\tau)^{\alpha}=0.64$. This illustrates the robustness of the uniqueness of BGP.

Transitional Dynamics and determinacy of Balanced Growth Path: I will now

\footnotetext{
${ }^{25}$ As in the literature, e.g., Benhabib and Gali [1995], the time preference seems to be too high, but that is inevitable to satisfy the tansversality condition and long-run growth condition simultaneously.
} 
study the determinacy of equilibria and the local stability properties around the BGP. Linearizing (14a) and (14b) around the unique BGP I found above, implies that the dynamics are approximated by the following linear system:

$$
\left[\begin{array}{l}
\dot{z} \\
\dot{\tau}
\end{array}\right]=\left[\begin{array}{ll}
J_{11} & 0 \\
0 & J_{22}
\end{array}\right]\left[\begin{array}{l}
z \\
\tau
\end{array}\right]
$$

where the Jacobian matrix is evaluated on the BGP. After some algebra, I can show:

$$
J_{11} \equiv \partial \dot{z} /\left.\partial z\right|_{B G P}=\rho>0 ; \text { and } J_{22} \equiv \partial \dot{\tau} /\left.\partial \tau\right|_{B G P}=A B \tau>0
$$

where

$$
\begin{gathered}
A \equiv[(1-\alpha-\tau) /[\tau(1-\tau)-(1-\alpha)(1-\alpha-\tau)]]<0 \\
B \equiv\left[\alpha((1+\gamma) / \gamma)(\theta /(1-\tau))^{1-\alpha} \tau^{-\alpha}[(1-\alpha-\tau)(1-\alpha) \tau(1-\tau)]\right]<0
\end{gathered}
$$

The trace-determinant combination of the Jacobian implies that there are two positive, unstable eigenvalues. Since both $z \equiv c / k$ and $\tau$ are jump variables, i.e., both $z(0)=c(0) / k(0)$, and $\tau(0)$ are free with given the initial $k(0)$, the dynamic system exhibits local determinacy and (saddle-path) stability. ${ }^{26}$ This guarantees the stability property of the second-best optimal capital tax policies to the economy in which government finance to the production sector plays the crucial role of endogenous long-run growth.

The above results are summarized by:

Proposition 3: If the parameters satisfy condition (18), the equilibrium path is locally determinant, and thereby there is a unique equilibrium path that converges to the unique Balanced Growth Path.

This is consistent with Benhabib and Perli [1994] who state that externalities

\footnotetext{
${ }^{26}$ Consider bifurcation points. When the share of tax revenues allocated to productive services is zero, i.e. $\theta=0$, (15) implies that $\tilde{\tau}$ disappears. Also, when $\theta=0, B=0$ in (20b) so that one eigenvalue becomes zero. Hence, the Jacobian vanishes and the qualitative results change. Accordingly, $\theta=0$ is a bifurcation point. At first sight, it seems that $\gamma=-1$ is also a bifurcation point. However, a negative $\gamma$ implies that private utility is decreasing in government consumption services, which contradicts a standard assumption on the utility function unless public consumption yields negative consumption externalities.
} 
(however large) are not enough to produce multiple equilibrium trajectories. It is also consistent with the suggestion of Benhabib and Gali [1995] that uniqueness of the equilibrium trajectory is preserved as long as a steady state is unique. Technically speaking, the uniqueness condition for a $B G P$ in Proposition 2 ensures the determinacy of equilibria in Proposition $3 .^{27}$ This also verifies Lucas' [1988] conjecture that all equilibrium paths converge to a balanced growth rate. Therefore, the growth convergence property extends to growth models with productive public services. Finally, the above numerical example also satisfies the sufficient condition for determinacy and convergence properties.

\section{Concluding Remarks}

This paper presented a basic endogenous growth model to study the role of optimal government consumption and production services in the growth process. I solved for commitment equilibria, and characterized the balanced growth path and the transitional dynamics of optimal tax policy and endogenous growth. This study justifies dynamic comparative analysis of the second-best fiscal policies in models of endogenous growth. For instance, the model can show how public consumption and production services affect a long-run economic performance when a government finances its revenue through distortionary taxes. This study also shows that the state-contingent fiscal policy is socially optimal under second-best policy instruments.

I close the paper with two possible extensions. First, it is interesting to see how robust the determinacy result is by adding more structure, e.g. endogenous labor decisions, and cross-effects between private and public consumption or between consumption and labor. In addition, once determinacy is overturned, this study is related to chaotic, or sunspots equilibria.

Second, we can study a multi-country version of this model so as to examine international interactions when fiscal policy activities in one country create externalities in other countries. Such a tax competition becomes an issue under the recent tendency of economic trading blocks. Moreover, it is also interesting to ask whether main results in this economy can be extended to in an integrated economy (e.g., Rivera-Batiz and Romer [1991]). This present model is simple enough for

\footnotetext{
${ }^{27}$ The uniqueness and stability results are an extension of those in Futagami et al. [1997] in a model of capital public stocks and the flat optimal tax, which does not permit to adjust intertemporal distortions.
} 
incorporating issues of an optimal size of club membership or integration of heterogeneous members when there are capital movements and public goods with cross-border externalities.

I leave these extensions for future work.

\section{Acknowledgement}

I thank Costas Azariadis, Antonis Demos, George Economides, Jim Malley, and Kazuo Nishimura, for comments and suggestions. My special thank for detail comments goes to the anonymous referee on this version and Byung Ho Song on an early version of this paper at Korean Economic Theory and Econometric Society Meeting in 2000. I also acknowledge 2002 Financial Support from Kyung Hee University.

Received 19 March 2003, Accepted 13 April 2004

\section{References}

Agell J., T. Lindh and H. Ohlsson [1997]: "Growth and the public sector: A critical review essay," European Journal of Political Economy 13, 33-52.

Alesina A. and D. Rodrik [1994]: "Distributive politics and economic growth," Quarterly Journal of Economics 109, 465-490.

Barro R. [1990]: "Government spending in a simple model of economic growth," Journal of Political Economy 98, S103-S125.

Basu S. and D. Weil [1998]: "Appropriate technology and growth," Quarterly Journal of Economics 113, 1025-1054.

Barro R. and X. Sala-i-Martin [1995]: Economic Growth. McGraw Hill. New York.

Benhabib J. and J. Gali [1995]: "On growth and indeterminacy: some theory and evidence," Carnegi-Rochester conference series on public policy 43, 161-211, NorthHolland.

Benhabib J. and R. Perli [1994]: "Uniqueness and indeterminacy: on the dynamics of endogenous growth," Journal of Economic Theory 63, 113-142.

Benhabib J., A. Rustichini and A. Velasco [1996]: "Public capital and optimal taxes without commitment," C.V. Starr Center Working Paper 96-19, New York University.

Benhabib J. and A. Velasco [1996]: "On the optimal and best sustainable taxes in an open economy," European Economic Review 40, 135-154.

Cazzavillan G. [1996]: "Public spending, endogenous growth and endogenous fluctuations," Journal of Economic Theory 71, 394-415. 
Chamley C. [1986]: “Optimal taxation of capital income in general equilibrium with infinite lives," Econometrica 54, 607-622.

Chari, V. V. and P. Kehoe (1999) "Optimal fiscal and monetary policy," in Handbook of Macroeconomics, vol. 1C, edited by J. Taylor and W. Woodford. North-Holland, Amsterdam.

Devarajan S., V. Swaroop and H. Zou [1996]: "The composition of public expenditure and economic growth," Journal of Monetary Economics 37, 313-344.

Devereux M. and J-F. Wen [1998]: "Political instability, capital taxation and growth," European Economic Review 42, 1635-1651.

Dreze J. and N. Stern [1987]: "The theory of cost-benefit analysis," in Handbook of Public Economics, vol. II, edited by A. Auerbach and M. Feldstein. North-Holland. Amsterdam.

Futagami K., Y. Morita and A. Shibata [1993]: "Dynamic analysis of an endogenous growth model with public capital," Scandinavian Journal of Economics 95, 607-625.

Glomm G. and B. Ravikumar [1997]: "Productive government expenditures and long-run growth," Journal of Economic Dynamics and Control 21, 183-204.

Guo J. and K. Lansing [1999]: "Fiscal policy, increasing returns, and endogenous fluctuations," Federal Reserve Bank of San Francisco, Working Paper 99-08.

Inman R. and D. Rubinfeld [2002]: "Subsidiarity, governance, and EU economic policy," CESifo Forum 3 (4), 3-11.

Judd K. L. [1985]: "Redistributive taxation in a simple perfect foresight model," Journal of Public Economics 71, 1-26.

Judd K. L. [1999]: "Optimal taxation and spending in general competitive growth models," Journal of Public Economics 71, 1-26.

Lee J. [1992]: "Optimal size and composition of government spending," Journal of the Japanese and International Economies 6, 423-439.

Kneller R., M. Bleaney and N. Gemmell [1999]: "Fiscal policy and growth: evidence from OECD countries,” Journal of Public Economics 74, 171-190.

Krusell, P., V. Quadrini, and J. V. Rios-Rull [1997]: "Politico-economic equilibrium and economic growth," Journal of Economic Dynamics and Control 21, 243-272.

Lucas R. [1999]: "Supply-side economics: an analytical review," Oxford Economic Papers 42, 293-316.

Lucas R. [1988]: “On the mechanics of development planning," Journal of Monetary Economics 22, 3-42.

Lucas R. and N. Stokey [1983]: "Optimal monetary and fiscal policy without capital," Journal of Monetary Economics 12, 55-93.

McKenzie L. [1987]: "Turnpike theory," in The new Palgrave: A Dictionary of Economics, Vol. 4, ed. J. Eatwell, M. Milgate and P. Newman, New York Stockton Press, 712-720.

Ortigueira S. [2000]: "A dynamic analysis of an endogenous growth model with leisure," Economic Theory 16, 43-62.

Park H. and A. Philippopoulos [2003]: "On the dynamics of growth and fiscal policy with 
redistributive transfers," Journal of Public Economics 87, 515-538.

Park H. and A. Philippopouplos [2004]: "Indeterminacy and fiscal policies in a growing economy," Journal of Economic Dynamics and Control 28, 645-660.

Persson T. and G. Tabellini [1992]: “The politics of 1992: Fiscal policy European integration," Review of Economic Studies 59, 689-701.

Rivera-Batiz L. and P. Romer [1991]: "Economic integration and endogenous growth," Quterly journal of Economics 106, 531-555.

Rebelo S. [1991]: "Long-run policy analysis and long-run growth," Journal of Political Economy 99, 500-521.

Seierstad, A. and K. Sydsæter [1987] Optimal Control Theory with Economic Applications, North Holland, New York.

Stiglitz J. [1987]: "Pareto efficient and optimal taxation and the new new welfare economics," in Handbook of Public Economics, vol. II, edited by A. Auerbach and M. Feldstein. North-Holland. Amsterdam.

Turnovesky S. [2000]: "Fiscal policy, elastic labor supply, and endogenous growth," Journal of Monetary Economics 45, 185-210.

Turnovsky S. and W. Fisher [1995]: "The composition of government expenditure and its consequences for macroeconomic performance," Journal of Economic Dynamics and Control 19, 747-786. 